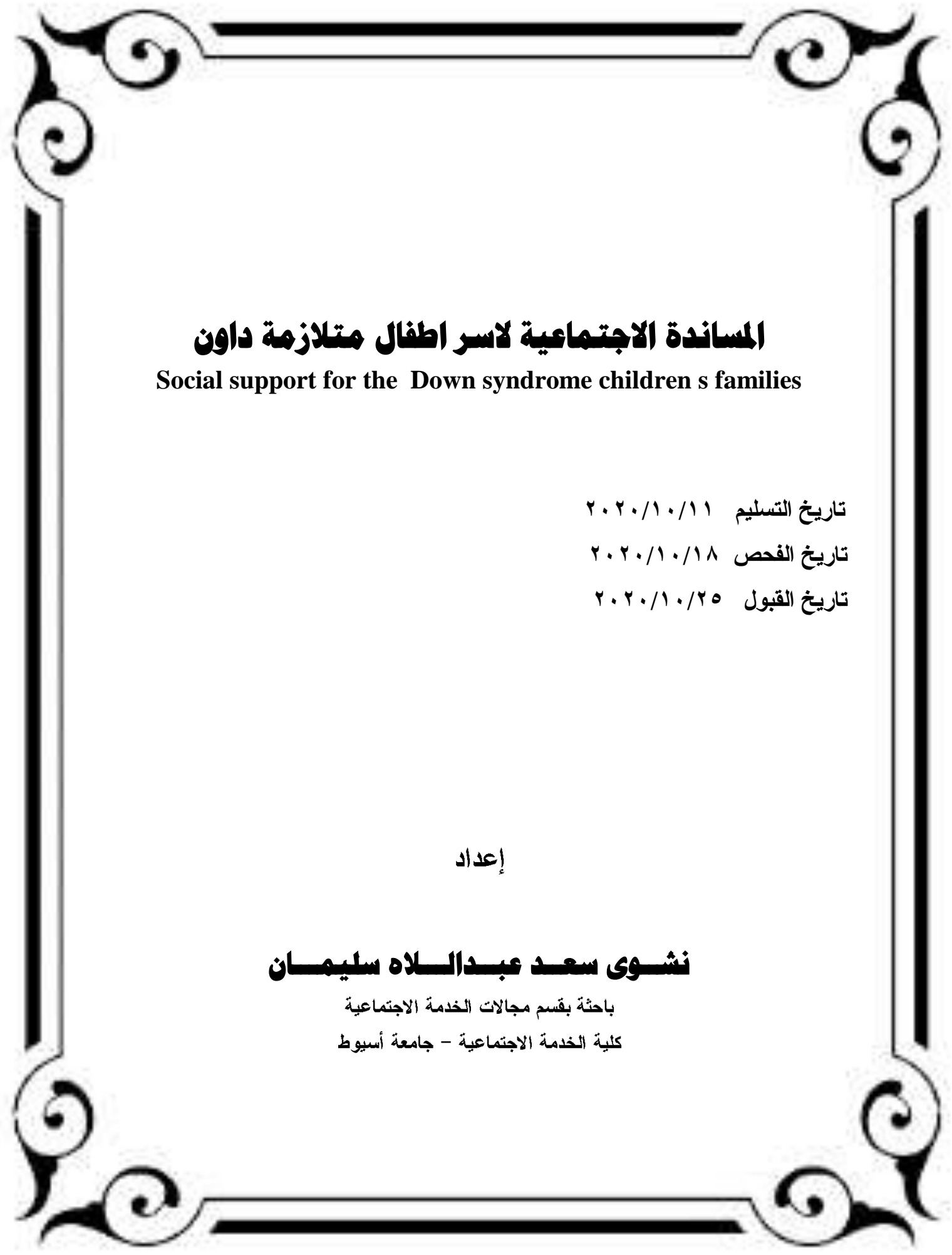



المسـاندة الاجتماعية لاسر اطفال متلازمة داون

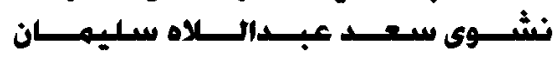

المجلة العلمية للخدمة الاجتماعية

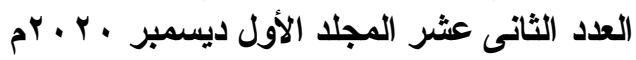

\section{المساندة الاجتماعية لاسر اطفال متلازمة داون}

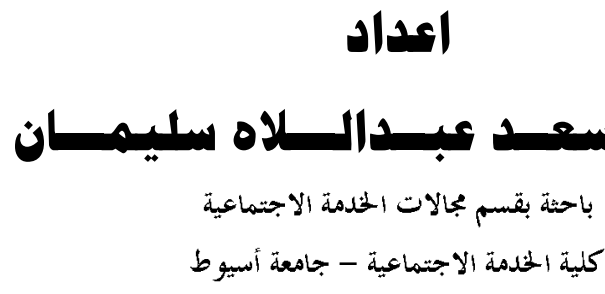

هلخص البحث:

الاسرة تتعرض لبعض المشكلات فمن الطبيعي ان ذلك يعيقها عن اداء وظائفها بالشكل الايجابي المتوقع من المجتمع ويالتالي فان التاثير لن يقتصر علي الاسره وحدها بل يمتد الي المجتمع باسرة علي تحقيق الهدافة لذلك كان من اولويات الخدمة الاجتماعية العمل علي مساعدة فالخدمة الاجتماعية كنظام اجتماعي اخر تتذخل بجهودها العلاجية

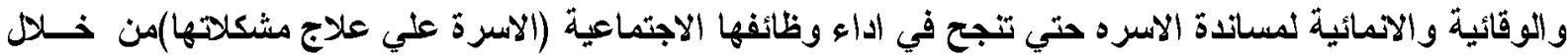
تقليم المساندة الاجتماعية لاسر الطفال داون . 
المسـاندة الاجتماعية لاسر اطفال متلازمة داون

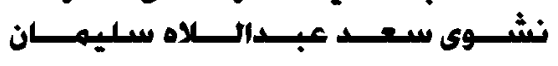

المجلة العلمية للخذمة الاجتماعية

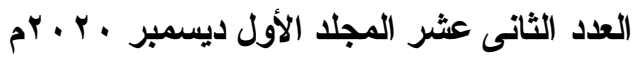

\section{Abstract}

The family is exposed to some problems, so it is natural that this hinders it from performing its functions in the positive manner expected of society, and therefore the effect will not be limited to the family alone, but rather extend to the community with a family to achieve goals. Therefore, one of the priorities of social service was to work to help, as social service as another social system interferes with its therapeutic efforts. And preventive and developmental support to support the family so that it succeeds in performing its social functions (the family resolves its problems) by providing social support to families of Down's children. 
المسـاندة الاجتماعية لاسر اطفال متلازمة داون

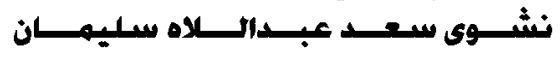

ثانيا :اهمية البحث

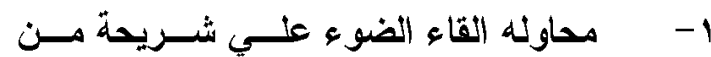
المجتمع والتعرن علي اشكال المســانده الاجتماعيـهـه للاصول الي البرامج التى يمكن ان تثبع احتياجـاتهم

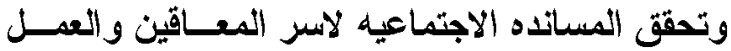

\section{علي تحقيقها.}

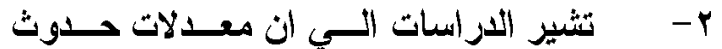

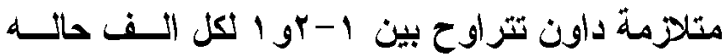

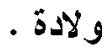

r- ت تعدد المشكلات التى تواجـهـ اســر اطفــال

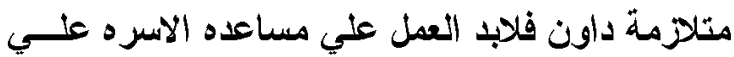
التعامل مع هذه المشكلات وتلبيه احتياجاتهم من خلال تحقيق المساندة الاجتماعيه لنه

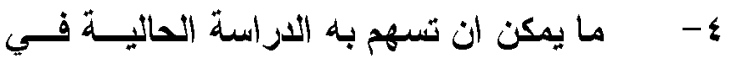

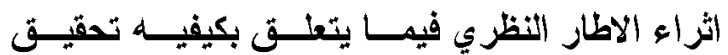
المساندة الاجتماعية لاسر اطفال متلامة داون .

\section{ثالثا :اهداف الدراسة : - ماست}

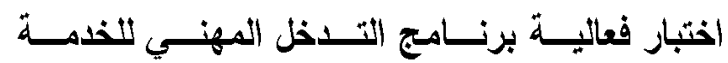

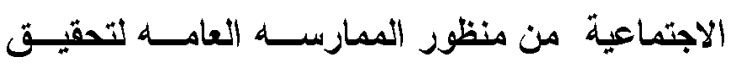

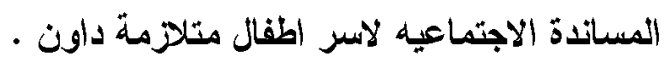

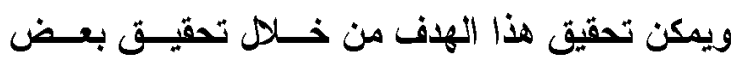
الاهداف الفرعية :

1- اختبار فعاليه برنامهج التدخل المهني للخدمه

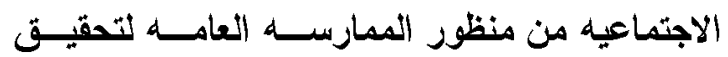
المسانده المعرفية لاسر اطفال متلازمه داون

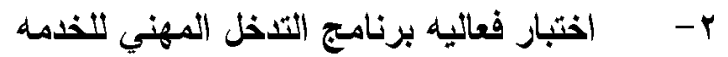

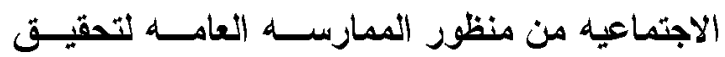
المسانده السلوكيه لاسر اطفال متلازمه داون r- اختبار فعاليه برنامهج التدخل المهني للخدمه

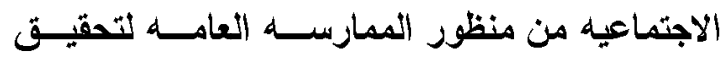
المسانده الوجدانية لاسر اطفال متلازمه داون
المجلة العلمية للخدمة الاجتماعية

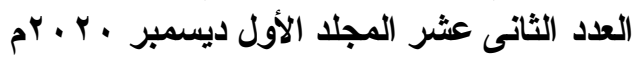

همشكلة البصث

وتعد متلازمه داون من اكثر الاعاقات الأهنية تزايــا

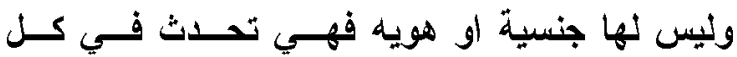
المجتمعات وفي كل الطبقات حيث اشـارت احصــائيات "الجعية الامريكية الوطنية لمتلازمه داون " الــي ان هناك اكثر من ، هـ الف شخص في الولايات المتحدة

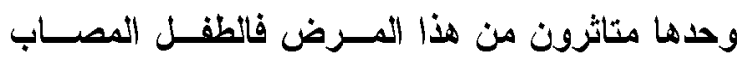

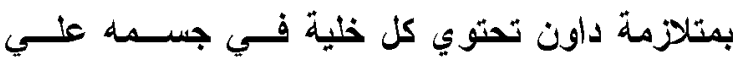

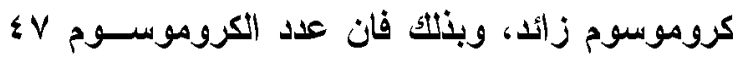
وليس צ\؛ كما هي الحال في الانسان العادي وتحديدا يكون هذا الكروموسوم الزائد في المكسـان الب مسن مخطط الكروموسومات. وتتعرض الأسرة للعديد من المشــاكل النفسـية

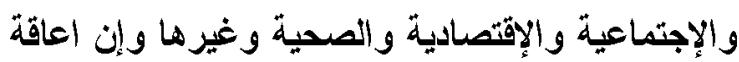

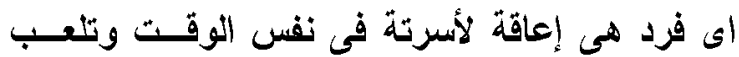

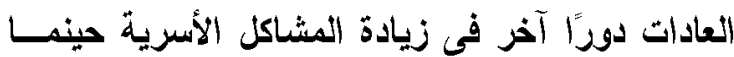

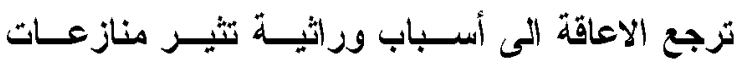
واضحة بين الزوبين.

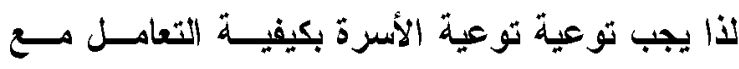

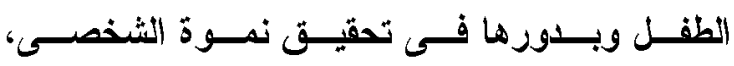

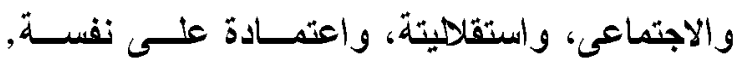

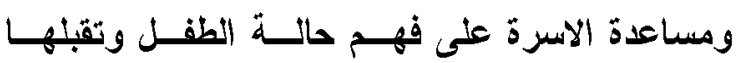

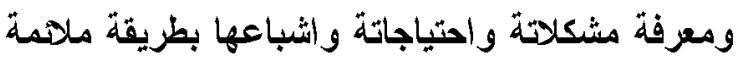

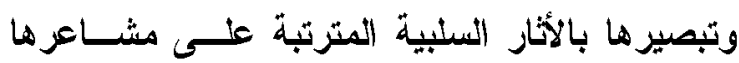
السنبية وتعريفها بالخدمات المتاحة للطفل في بيئتـة المحلية وكيفية الحصول عليها. ولكي تتظلب الأسرة على تلك المشاكل التى تواجههــا

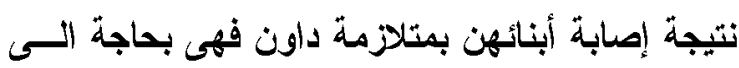

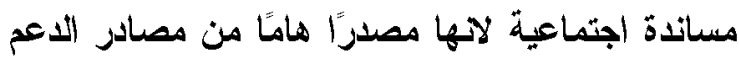

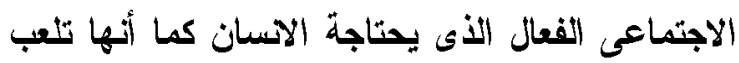

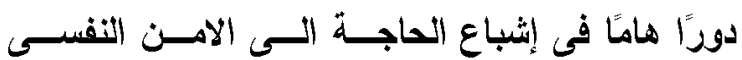

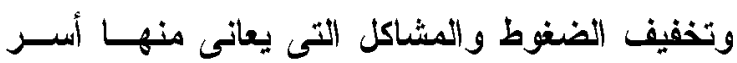

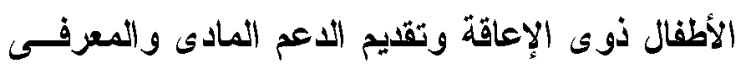

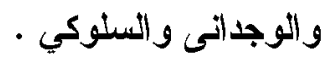


المسـاندة الاجتماعية لاسر اطفال متلازمة داون

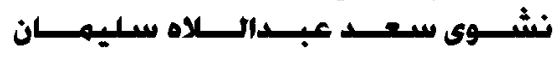

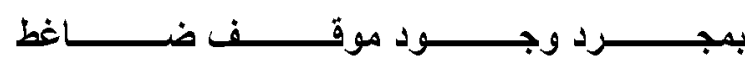

(V,Hoorens, B, Buunk, 1992,p445).

r- ب بتلازمة داون

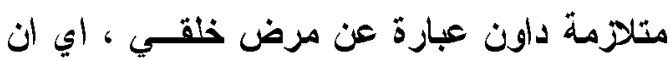

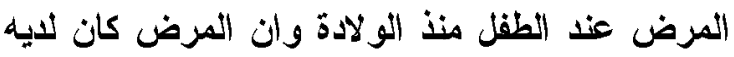

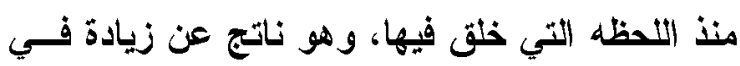

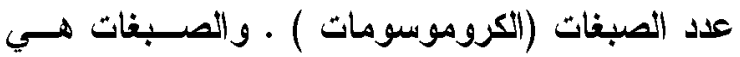
عبارة عن عصيات صغيرة داخل نواة الخلية، تحمـل هذه الصبغات في داخلها تفاصيل كاملة لخلق الأسان،

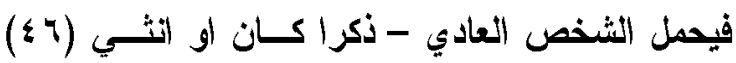
كروموسوم فان متلازمة داون ناتجه عن زياده فـي الكروموسومات فيكون عـدد الكروموسـومات (V) كروموسوما بدلا من العدد الطبيعي (؟ (؟).

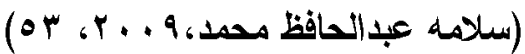
سادسا :دراسات سابقة للبمث دراسات تناولت المساندة الاجتماعية :

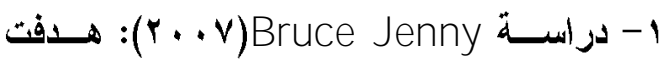
الاراسة إلى تعديا دور المساندة الإجتماعية

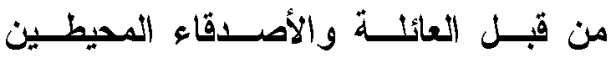

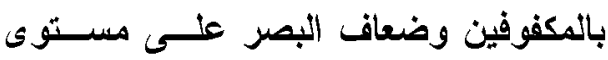

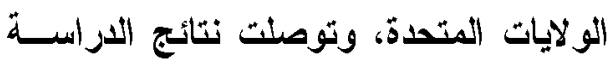
إلى أن دور المساندة الإجتماعية مـنـ ثبـل

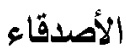

و العائلة المحيطين بالمكفوفين وضعاف البصر تشـير

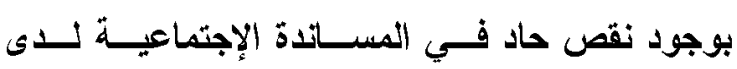
المكفوفين وضعاف البصر للتلك ينبغى زيادة التركيـز

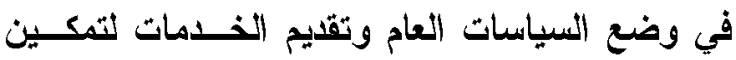

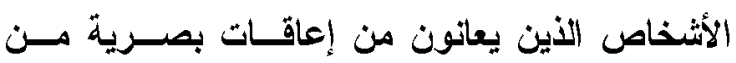
المساندة الإجتماعية.

Athanasopoulos, Vassilios براسية

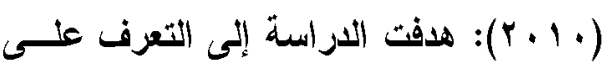

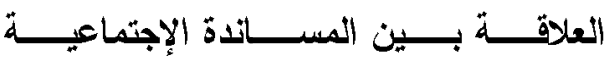

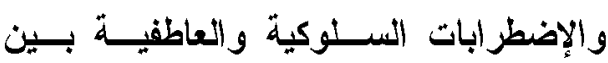

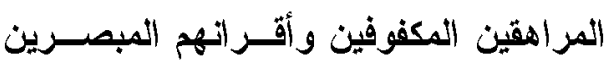
وتوصلت نتائج الاراسة إلى فروق ذات دلالة
رابعا :فروض الدراسة :

وتتثثل فروض الاراسة الحالية في الفرض الرئيسـي : مروضي

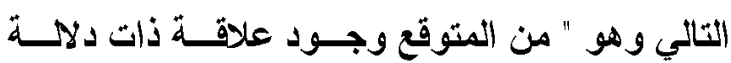

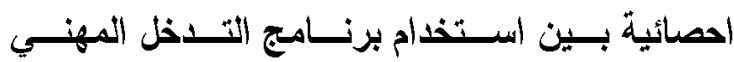

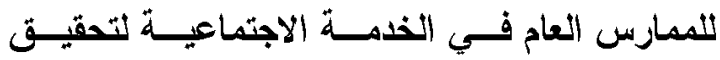
المسانده الاجتماعيه لاسر اطفال متلازمة داون.

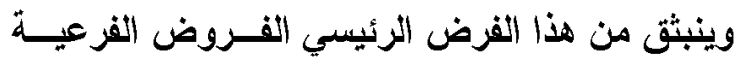
الاتية : اليان

1- - من المتوقع وجود علاقة ذات دلاله احصائية

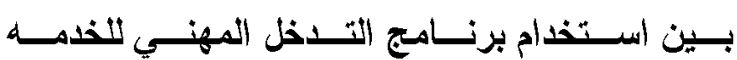
الاجنماعيه من منظور الممارســـه العامــه لتحقيــث المسانده المعرفية لاسر اطفال متلامهه داون . r - بن المتوقع وجود علاقة ذات دلاله احصائية

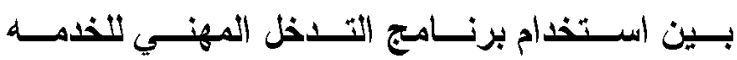
الاجتماعيه من منظور الممارســـه العامــه لتحقيـتق المسانده السلوكية لاسر اطفال متلازمه داون ـ r- من المتوقع وجود علاقة ذات دلاله احصائية

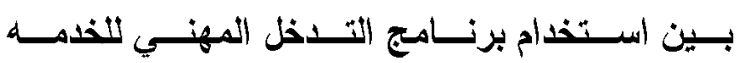
الاجتماعيه من منظور الممارســـه العامــه لتحقيـتق

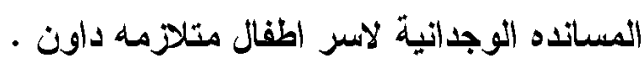

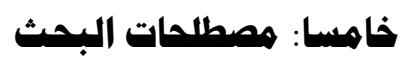
1-المساندة الاجتماعية :

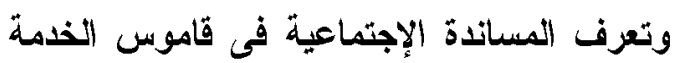

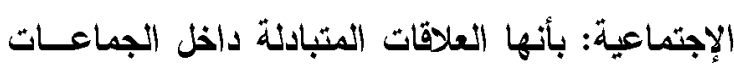

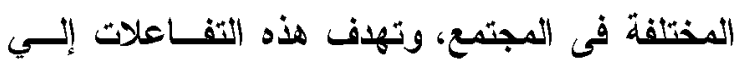
إثباع احتياجات الفرد النفسية والمعرفية و العاطفيـة وتهية والإجتماعية، وتثشكل هذه الجماعات من عدد قليل من

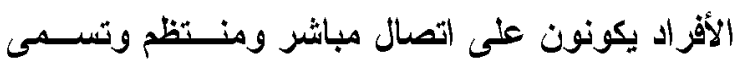
بجماعات المساندة. ( Cutrona,1996,p15) وتعني المساندة في المورد على إنها: المساعدة،

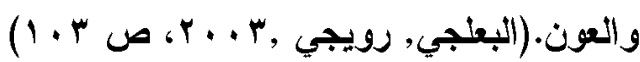

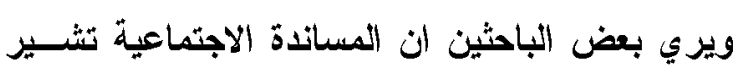
الي التلقي الواقعي للاعمال المساندة مـن الاختـرين 
المسـاندة الاجتماعية لاسر اطفال متلازمة داون

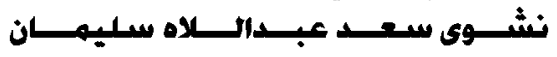

الممارسة المهنية للخدمة الاجتماعية بمجـال رعايــة

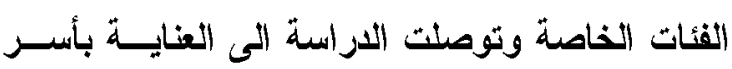

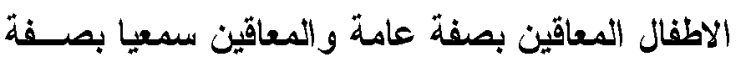

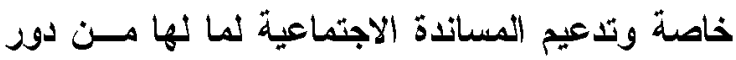
فى خفض حدة الضغوط التى تعرض لها الام والاسرة من وجود طفل معاق.

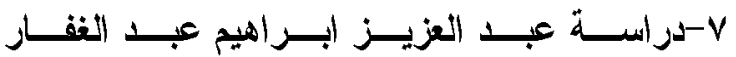

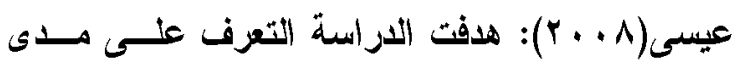
اهية المساندة الاجتماعية في رعاية وتأهيل المعاثين بذنيا او حركيا والحاقه بفرص العمل التــ تناســبـ

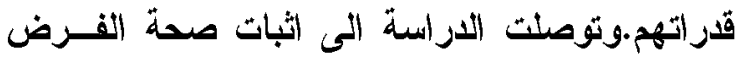
توجد فروق دالة احصائيا عند مستوى معنوية (ه. .) بين تأهيل المعاثين بدنيا فمن يلقون مساندة مجتمعية وتأهيل المعاقين بدنيا فعن لا يلقون مساندة مجتمعية. الاطار التطبيقي للبحثي

\section{سابعا : هنهج البحث واجراءتة:}

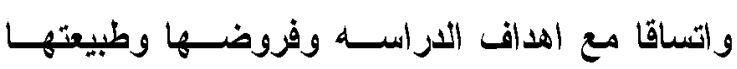

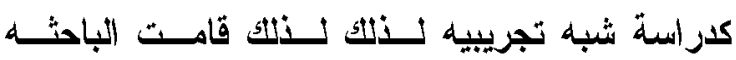
باستخدام المنهج التجريبي باستخدام مجموعه واحده

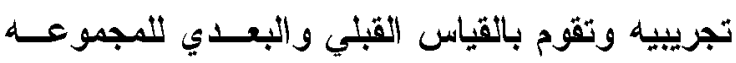
نفسها وقياس عائد التذخل المهني علــي المجموعـهـ

نفسها . نفان

\section{ثاهنا: ادوات الدراسة:}

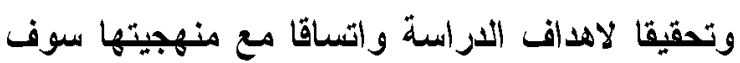

$$
\text { تعتمد الدراسه علي الادوات الاتيه : }
$$

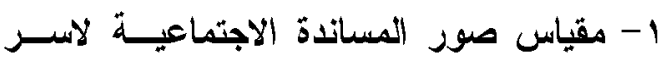

متلازمة داون وهو من اعداد الباحثة :

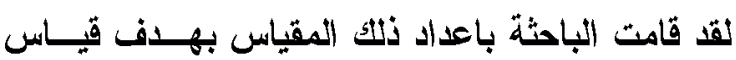

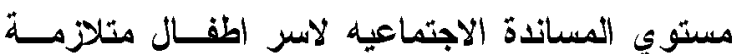

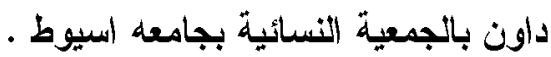

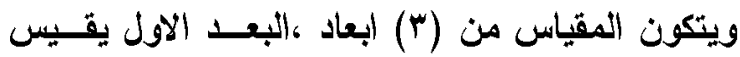

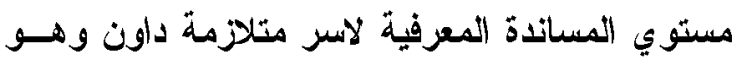
مكون مسن (ع ا)، والبعـدالثاني ويقـيس مســتوي المساندة السلوكية وهو مكون مسن (ك 1) ، والبعـد

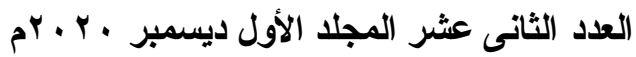

إحصائية بشأن الإضطر ابات المتعقة باتنكيف

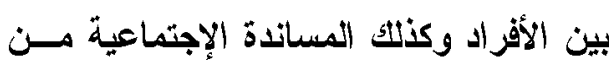

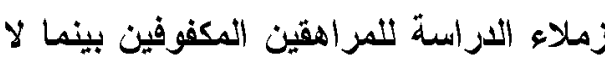
توجد فـروق ذات دلامسة إحصـائية بـين المراهقين المبصرين بثــأن الإضــطرابات الماته السلوكية و العاطفية وكنلك الدعم الإجتماعى.

Guerette,Amy

R.\&

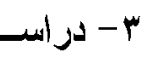
(2011)Smedema,Susan Miller

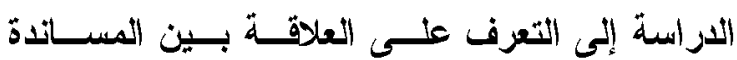
الإجتماعية ومؤشر ات متعددة من الرفاهيــة للبــالغين

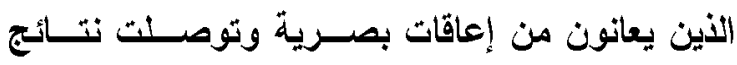

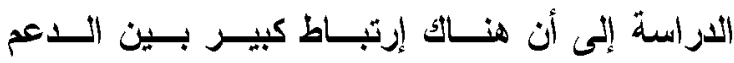
الإجتماعى وأعراض الإكتئاب والرضا عن الحياة.

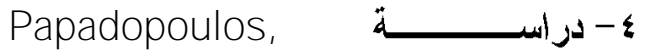

(2014) Konstantinos \& Others

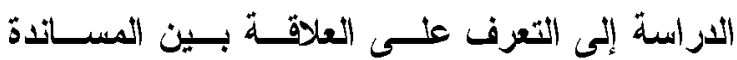
الاجتماعية والإكتئاب بين البالغين المكفوفين وتوصنت نتائج الدراسة إلى أن هناكَ علاقهـة بـين المســاندة الإجتماعية والإكتئاب وأن الــدعم العـاطفى المقــدم

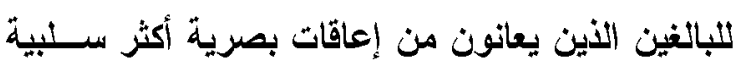
وارتبط بثكل كبير مع أعز اض الإكتئاب.

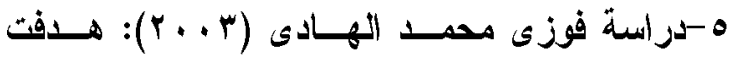

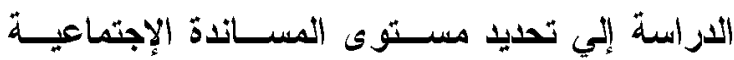
المقدمة لمرضى الأمراض المزمنة في حالة الإصـابة الإبية

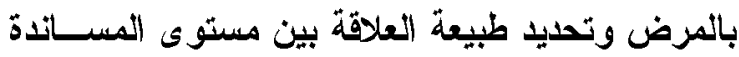

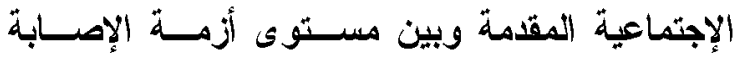

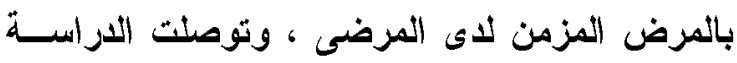

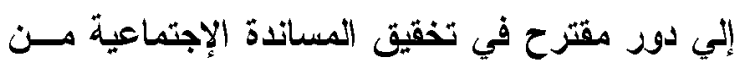
خلال المساندة الإجتماعية من خلا لمان المساندة العاطفية

و الموجدانية و المساندة التفاعلية و المساندة المعرفية.

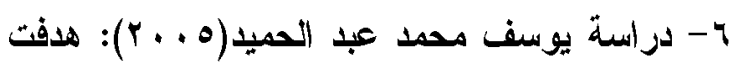
الار اسة تحديد طبيعة واشكال المســاندة الاجتماعيـة المقدمة لامهات الاطفال المعاثين سمعيا وكذلك طبيعة ولئل

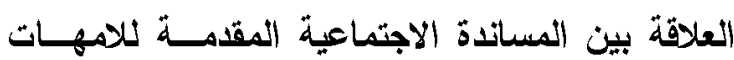

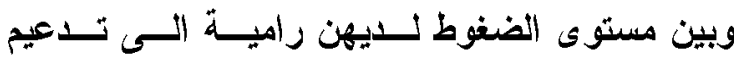


المسـاندة الاجتماعية لاسر اطفال متلازمة داون

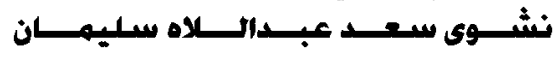

خلال تلأبك الخطــوه للباحثـة

ماهية المسـاندة الاجتماعيـة

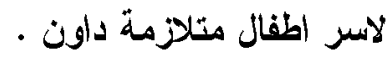

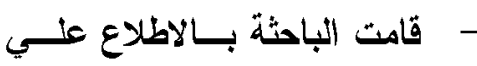

العليد من الاراسات العلميـة

والاجنبية المرتبطة بموضسيوع

المساندة الاجتماعيــة لاستـر بهر

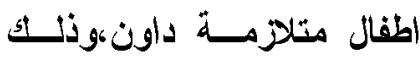

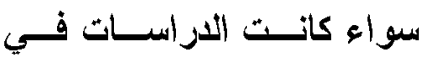

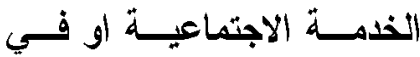

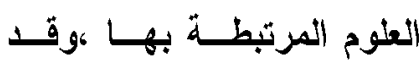

اتضعح من خلال تلاتك الخطــوة

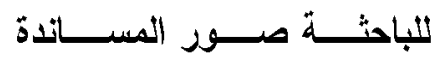

الاجتماعية لاسر اطفال داون .

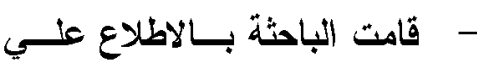

العليد من المقاييس في العديد

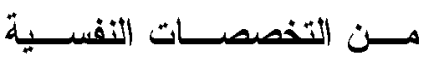

والاجتماعية والتي صمثت من

اجل قياس مستوي المسـاندة

الاجتماعيه التي تتعرض نهـا

اسر المعاقين بصـفه عامسه

واســر اطفــال داون بصــفة بهـة

$$
\text { خاصة . }
$$

ب- المرحلة الثانية- صياغة المقياس فـي صورتنه الاوبية:

1- في اطار الاطلاع عـــي التقــارير

والتزاث النظري و الاراسات العلمية النية

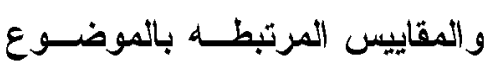

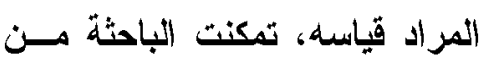

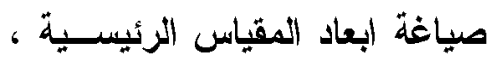

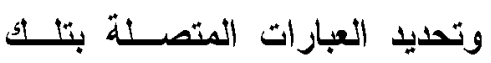

الابعاد ، وقد اشتمل المقياس فـي

صورته المبدائية علي ثلاثة ابعساد

والتي تم وضــع مجموعـة مسند
المجلة العلمية للخدمة الاجتماعية

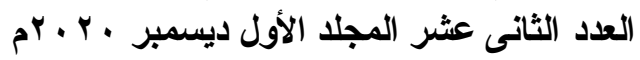

الثالث ويقيس مستوي المساندة الوجدانية وهو مكون

من (1)

وقا راعت الباحثه في اعدادها لهزا المقياس مجموعه من الخطوات والاجراءات والمعايير العنيه المنهجية اعنية

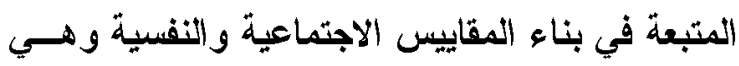
كالتالي :

أ- المرحلة الاولــيـ- الاعـــاد المبــئي

$$
\text { لانمقياس : }
$$

1 - تحيد موضوع المقياس في ضــو

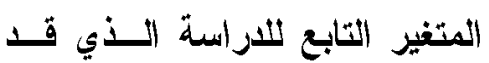

يحدث نتيجة التخل المهني والأي

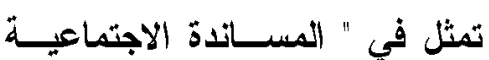
لاسر اطفال متلازمة داون " لاوني

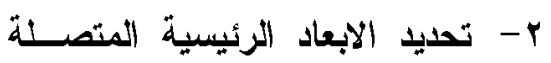

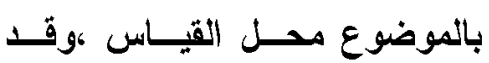

تمثلت هذه الابعاد في ثلاثنه ابعـاد

$$
\text { رئيسية وهي كالثالي : }
$$

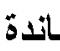

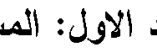

المعرفية.

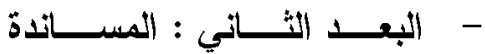

السئوكية.

- البعــــ الثالـــث : المســــاندة

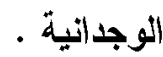

r- جمع العبارات المتصــلة بالابعـاد

الرئيسية للمقياس ونلتك من خـلدل

الاتي :

- قامت الباحثة بـالططلاع علــي

العليد مـن مراجـع التــراث

النظــــي العربــي والاجنبــي هني

المرتبط بموضــوع المســاندة

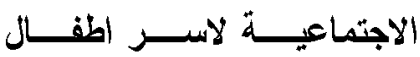

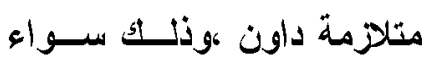

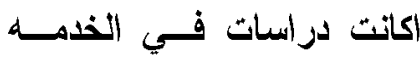

الاجتماعيــة او فــي العلــوم

المرتبطة بها ، وقد اتضح من 
المسـاندة الاجتماعية لاسر اطفال متلازمة داون

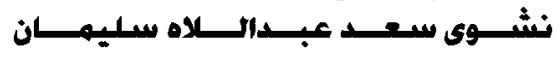

عبار ات اخري يمكن اخذها من

المبحوثين.

د- المرحة الرابعة:-هرحلة تقتين المقياس:

وتقنين المقياس يتم من خلا حساب الصدق والثبات

ويمكن عرض ذلتك من خلال الاتي:

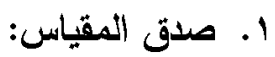

ويعتبر صدق المقياس عن مدي تحقيق الاداء البحثية

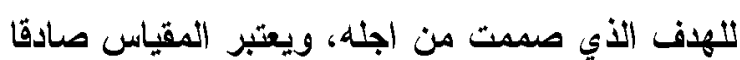

أذا كان يقيس الصفة والقدرة التـي قصـــ ثياســها

ولتحقيق ذلاك قامت الباحثة باستخدام ثلانة انواع مسن فئن

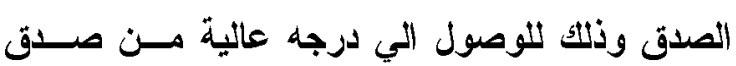
المقياس من خلال التالي :

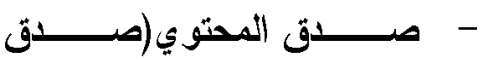

$$
\text { (المضمون): }
$$

تحقيق هذا النوع من الصدق قامت الباحثة بالاتي:

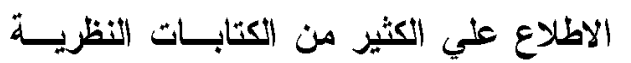

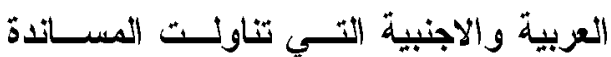

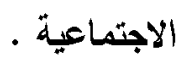

الاطلاع علي الكثير من الدراسات والبحسـوث

العربية والاجنبية المتعلقه باسـر متلازمسة

داون ، و المتعقله بالمساندة الاجتماعية.

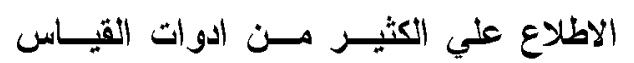

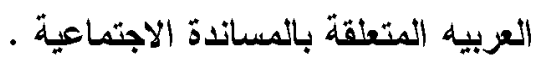

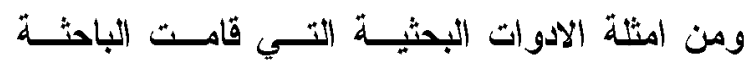

بالاطلاع عليها هي :

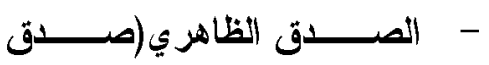

\section{(المحكمين )}

والأي تم التحقى منه من خلال عرض المقياس عنـي

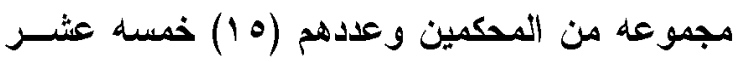

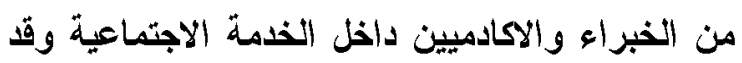

تم التحكم علي المقياس في ضوء عدة معايير هي : • مدي سلامه الصياغة للعبارة ووضوحها. • دي ارتباط العبارة بالبعد الأبي تقيسهة.
المجلة العلمية للخدمة الاجتماعية

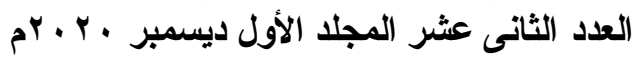

العبارات والمؤشرات الدالة عليها ،

وهذه الابعاد هي كالتالي:

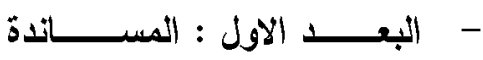

المعرفية.

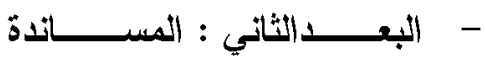

السبوكية.

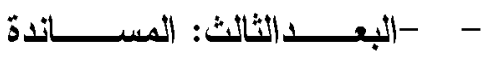

الوجدانية.

r- صياغة العبارات المتصلة بالابعـاد

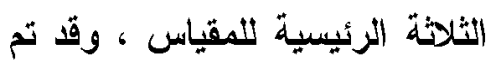

مر اعاد ذللك في تصــيم العبـار اتئه

الاثيه:

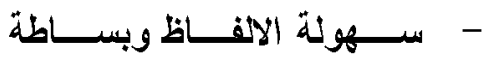

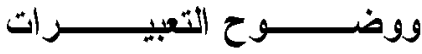

المستخدمة.

- الاعكون العبارات مركبة بحيث

تتضمن العبارة فكــة واحـــة

فقط.

r- قام الباحث باتباع الثروط العلميـة

لصياغة العبارات في الثناء اعـداد

هذا المقياس، ومن ثم اعتمد عنـي

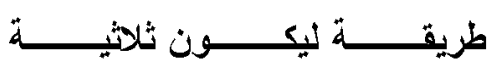

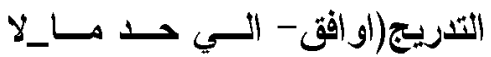

اوافق) والتى تيناسب ميع الغــرض

الأذي صمم من اجله المقياس .

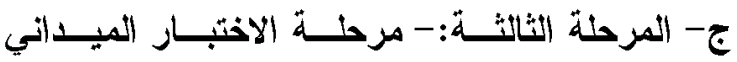

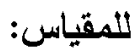

وبعد الصياغة المبدائية للمقياس كان لابد من اجـراء

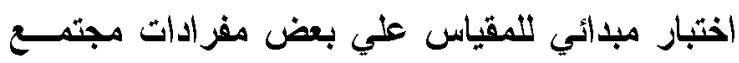

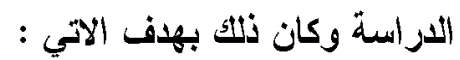

ا. التاكد من ملاهمــة ووضــوح

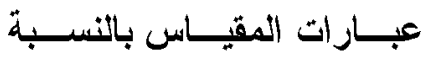

للمبحوثين.

r. التاكد مـن ان كافــة الابعـاد

الخاصة بالمقياس لاينقصــها 
المسـاندة الاجتماعية لاسر اطفال متلازمة داون

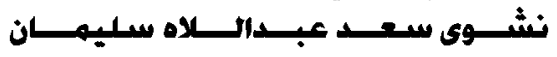

المجلة العلمية للخدمة الاجتماعية

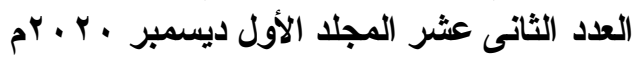

• اضافة او حذف بعض العبارات علي حسـب وجهة نظر المحكم.

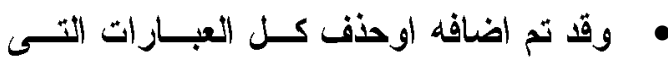

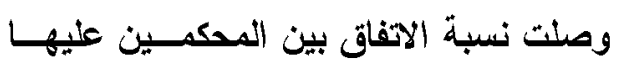

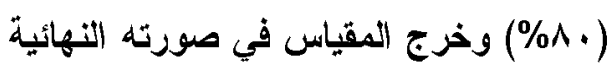

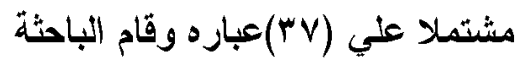

بحساب نسبة الاتفاق على العبارات بين الساده المحكمين من خلا ولام المعادية الآتية: عدد مرات الاثفاق

نسبة الاحفاق

$\dot{u}$

حيث ن = عدد السادة المحكمين.

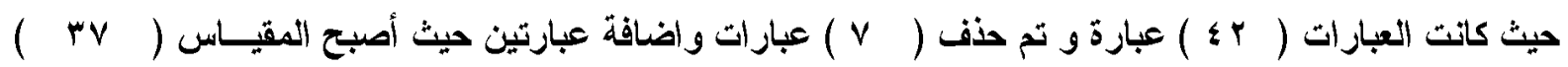
عبارة فى صورته النهائية .

المقياس علي نفس المفردات بع مرور (1 1)يوم من تاريخ التطبيق الاول

واهم الوسائل الاحصائية التي استخلمتها الباحثة هي

: -

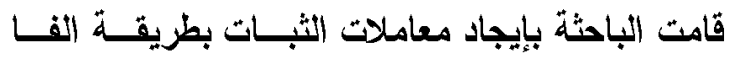
كرونباخ على عينة قو امها (10) مفردة ممثلة للعينة

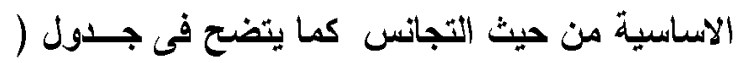

r- ب بات المقياس: بعد ثبات المقياس شرطا اساسيا من شروط استخدامه

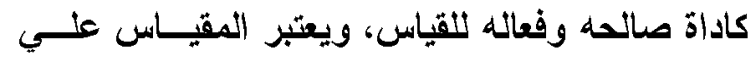
درجة عالية من الثبات اذا تم الحصول عنـي نفسـس

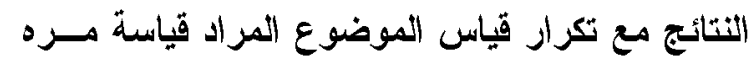
اخري بنفس الاداء ميع نفس المبحوثين وميع وجـود

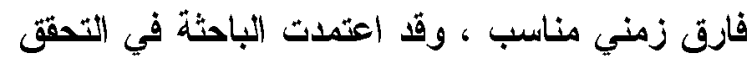
هن ثبات المقياس علي طريقة اعادة الاختبار. وقد قامت الباحثة بتطبيق المقياس علــي مجموعـهـ

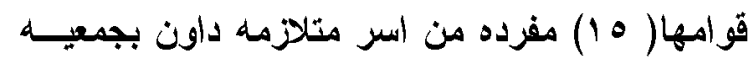

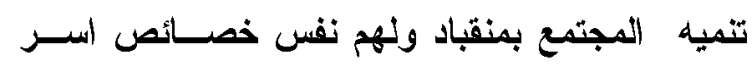

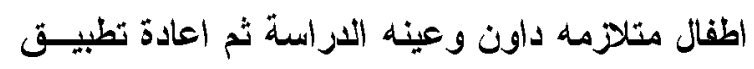
جدول ( )

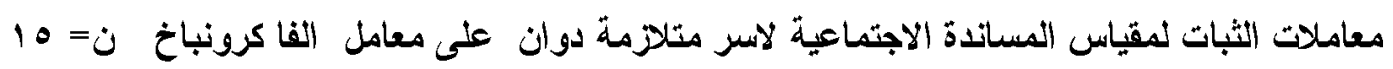

\begin{tabular}{|c|c|}
\hline معاملات الثبات & أبعاد المقياس \\
\hline$\cdot . \wedge \wedge \mu$ & " المساندة المعرفية" \\
\hline..$\wedge \wedge \varepsilon$ & " المساندة السلوكية" \\
\hline.$\wedge \wedge 4$ & المقياس ككل \\
\hline
\end{tabular}


المساندة الاجتتماعية لاسر اطفال متلازمة داون

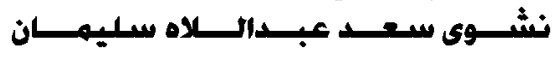

كما قامت الباحثة بإيجاد معاملات الثبـات بطريقــة

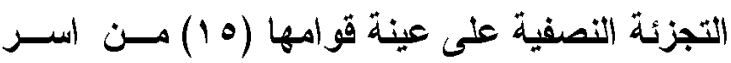

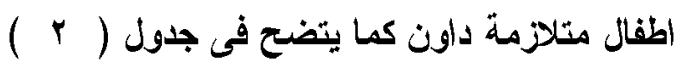

المجلة العلمية للخدمة الاجتماعية

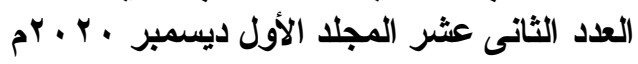

\section{جذول ( r )}

معاملات الثبات بطريقة التجزئة النصفية على اداة بطاقة الملاحظة لاسر اطفال متلازمة داون ن= 10

\section{Coefficient

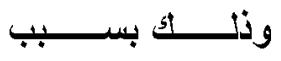 \\ اختلاف معامل الفا \\ كرونباخ للنصـفين ستفن}

\begin{tabular}{|c|c|}
\hline هعامل الثبات & الاداة \\
\hline$. .9 \leq$. & الاداة ككل \\
\hline
\end{tabular}

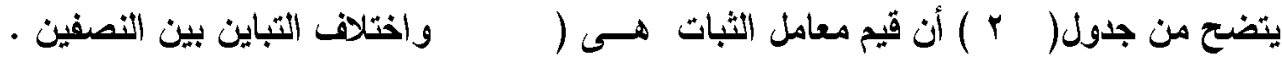

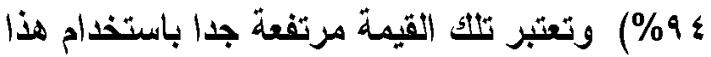
يدل على ثبات المقياس وتم اختيار معامل التجزئة

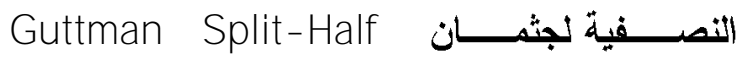
تاسعا: هناقشة النتائج

جدول (r)

يوضح نسبة التفيير في أبعاد استمارة مقياس المساندة الاجتماعيه لاسر اطفال متلازمة داون

$(10=0)$

\begin{tabular}{|c|c|c|c|c|c|c|c|c|c|}
\hline \multicolumn{2}{|c|}{ التغيير } & \multicolumn{3}{|c|}{ بعد التذخل } & \multicolumn{3}{|c|}{ قبل التدخل } & \multirow[t]{2}{*}{ لابـعاملات الإحصائية } & \multirow[b]{2}{*}{ r } \\
\hline بترتي & نسبة & أنسبة & المسابـ المرجط & مجمو & النسة & التوسط المسبى & مجمو ع الأوزا & & \\
\hline r & $\leqslant 1$ & AA.T & T.Y. & 017 & $\begin{array}{c}\leq V . \\
r\end{array}$ & $1 . \leqslant r$ & $r v q$ & المساندة المسزفية & 1 \\
\hline 1 & 01.1 & 94.0 & Y.A & $\leq 7 r$ & $\begin{array}{c}\leq r . \\
\leqslant\end{array}$ & I.rV & Y. & المساندة السلوكية & r \\
\hline$r$ & ד & А५. & T.४A & $0 . \varepsilon$ & $\begin{array}{c}01 . \\
7\end{array}$ & 1.00 & $r \cdot r$ & المساندة الوجدانية & $r$ \\
\hline & $\leqslant 1$ & $\wedge \wedge .9$ & T.YV & $\begin{array}{c}1 \leq 1 \\
1\end{array}$ & $\leqslant$ \& & $1.2 \leqslant$ & $\vee 9 \wedge$ & 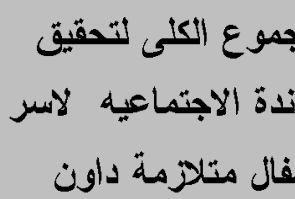 & \\
\hline
\end{tabular}


المسـاندة الاجتماعية لاسر اطفال متلازمة داون

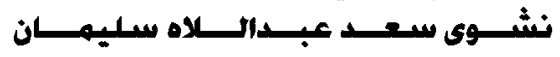

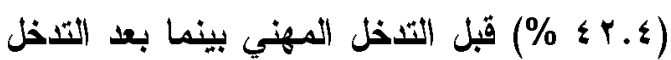

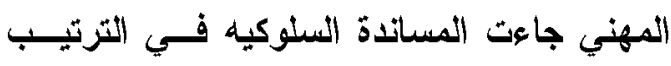

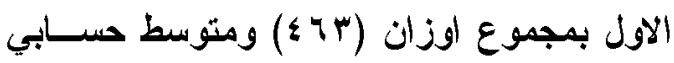

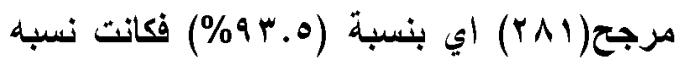

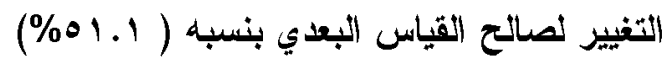

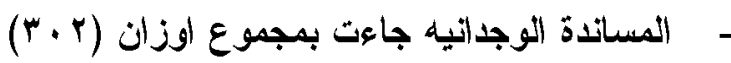

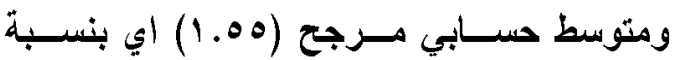

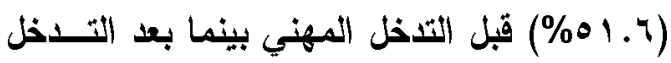
المهني جاءت المساندة الوجدانية جاءت بمجموع

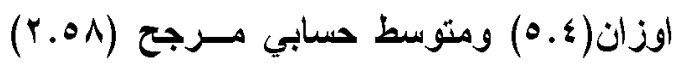

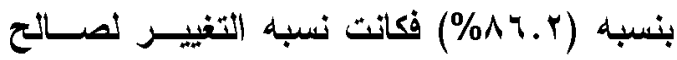

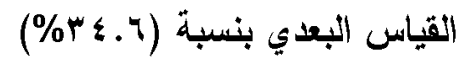

المجلة العلمية للخدمة الاجتماعية

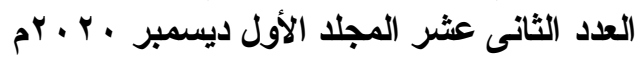

يوضح هذا الجدول نسبة التغير فـي ابعـاد مقيـاس

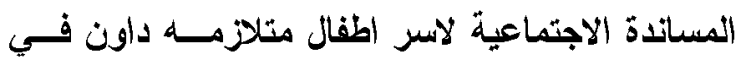
الاتي: - مVالمساندة المعرفية جاءت بمجموع اوزان (rv) -

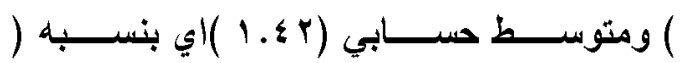

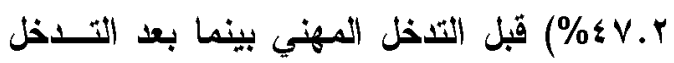

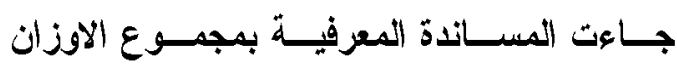

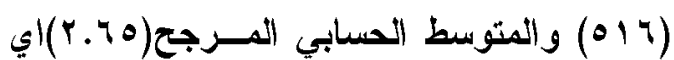

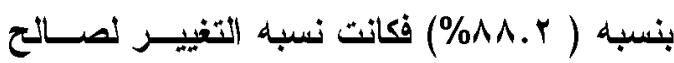

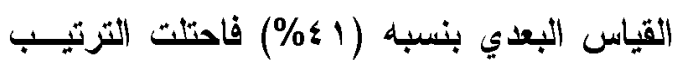

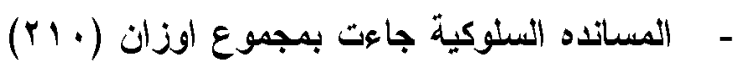

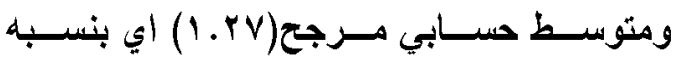

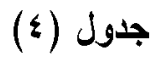

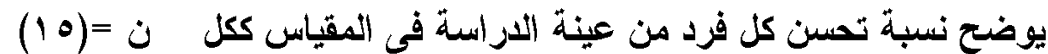

\begin{tabular}{|c|c|c|c|c|}
\hline الترتيب & نسبة التحسن & $\begin{array}{c}\text { نسبة الأداء فى القياس } \\
\text { البعدى (\%) }\end{array}$ & 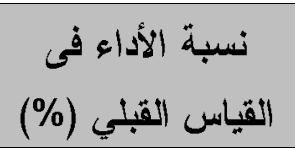 & المبحوث \\
\hline ir & ry & Qr.A & 04.1 & 1 \\
\hline 10 & rq.V & $\Lambda 9 . r$ & 09.0 & r \\
\hline 1. & $\{. .7$ & $\wedge q . r$ & $\leq \Lambda .7$ & $r$ \\
\hline$v$ & $\leqslant r . r$ & A4.० & $\leq r . r$ & $\varepsilon$ \\
\hline$r$ & $\leqslant 9.0$ & $a r . \wedge$ & $\varepsilon r . r$ & 0 \\
\hline$r$ & $01 .\{$ & Q & $\leqslant$ S.r & 7 \\
\hline ir & ro.q & $q u . V$ & $\leq 4.1$ & $v$ \\
\hline 11 & $r 4.9$ & $\Lambda \vee . \varepsilon$ & 0.0 & $\wedge$ \\
\hline 1 & or.r & Q r.A & $\leq . .0$ & 9 \\
\hline D & $\leq 4.9$ & $\Lambda \Lambda . r$ & $\leqslant 1 . \leqslant$ & 1. \\
\hline$\varepsilon$ & $\leq \Lambda . V$ & QY.V & so & 11 \\
\hline 7 & $\leqslant 4$ & $\Lambda \Lambda . r$ & $\varepsilon r . r$ & ir \\
\hline$\wedge$ & $\leqslant$ ใ. \{ & A Q.r & $\leq 4 . \wedge$ & ir \\
\hline 9 & $\leqslant$ S.r & qr.V & $01 . \varepsilon$ & $1 \varepsilon$ \\
\hline $1 \varepsilon$ & $r . .7$ & 11.1 & 0.0 & 10 \\
\hline
\end{tabular}


المسـاندة الاجتماعية لاسر اطفال متلازمة داون

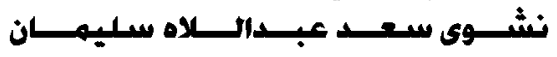

بين استخدام برنامهج التـــخل المهنــي مـن منظــور

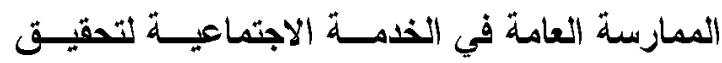
المساندة المعرفية .

r- نتائج اختبار الفرض الفرعي الثاني : "تـن

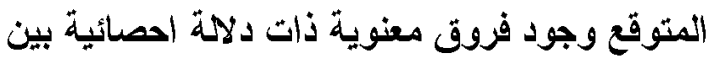
استخدام برنامج التخخل المهني من منظور الممارسة

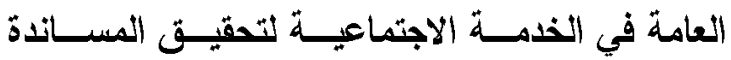
السلوكية لاسر اطفال متلازمة داون " ويتضع ذلتك من

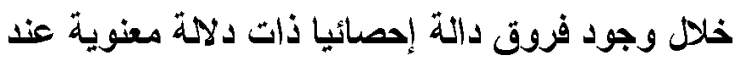

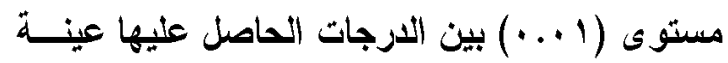

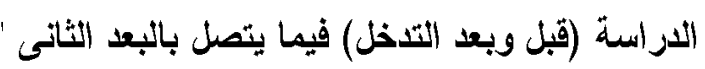

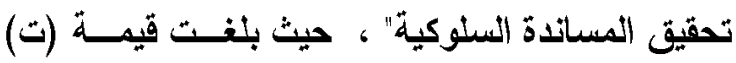

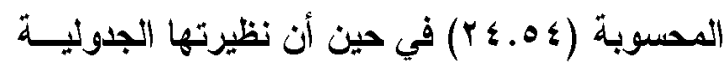

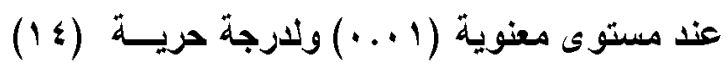

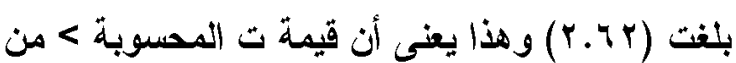

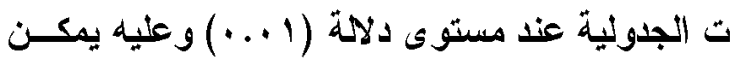

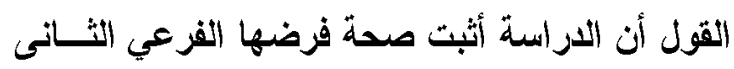
بحدود ثقة (99 . .) وجود فروق ذات دلائة إحصـائية

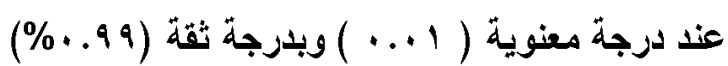

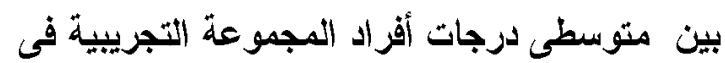

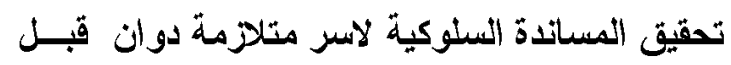
وبعد التخل المهنى لصالح القياس البعدى .

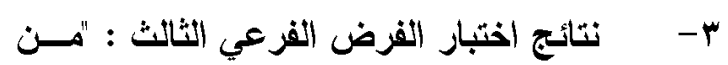

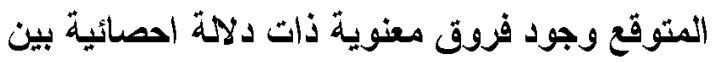
استخدام برنامجج التذخل المهني من منظور الممارسة

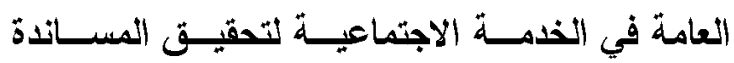

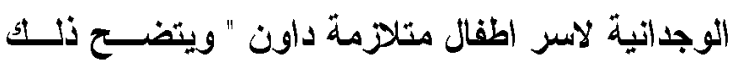

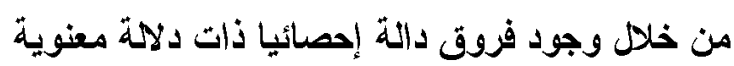

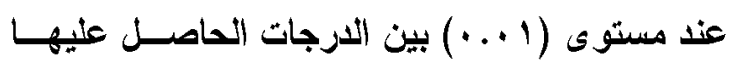

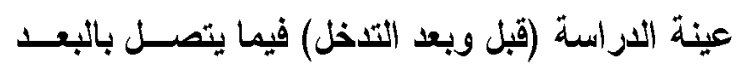

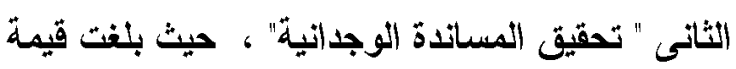

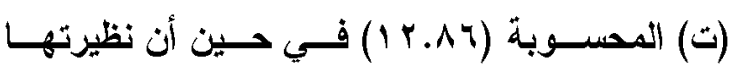
الجدولية عند مستوى معنوية (1 +. ..) ولثرجة حرية

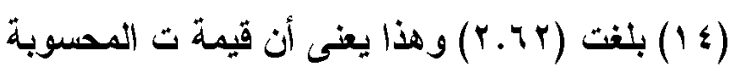

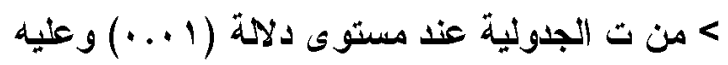

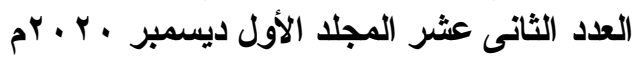

يتضح من الجدول السابق أعلى مبحوث تحسن مسن

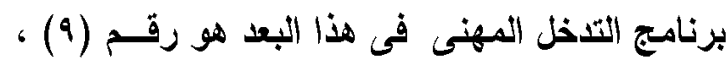

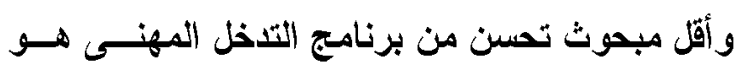

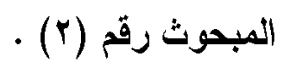

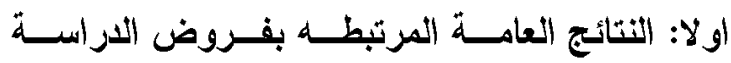
الخاصة بابعاد القياس : في ضوء النتائج التي اسفرت عنها الارساسة ،يمكـن

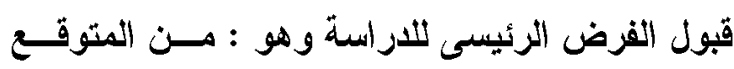

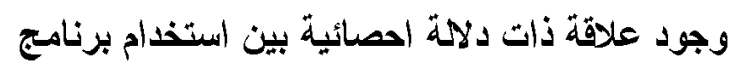

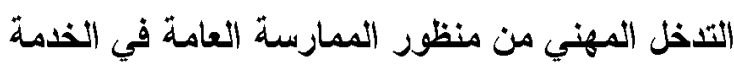
الاجتماعية لتحقيق المساندة الاجتماعية لاسر اطفال متلازمة داون ويمكن مناقشة زلتك من خلال نتائج اختبار ات الفروض الفرعية الاتية : 1- نتائج اختبار الفرض القرعي الاول : " مـن

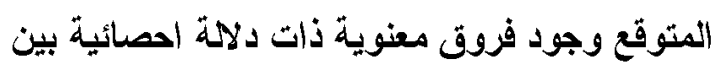
استخدام برنامج التخل المهني من منظور الممارسة

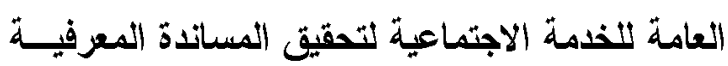

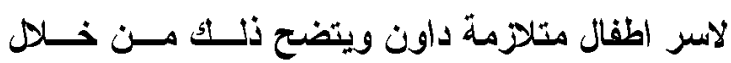

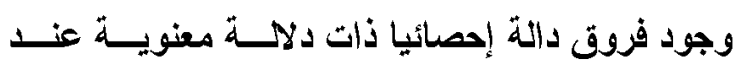

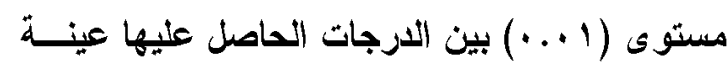

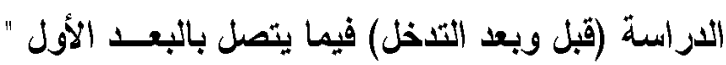

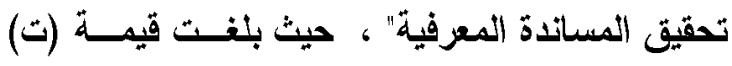

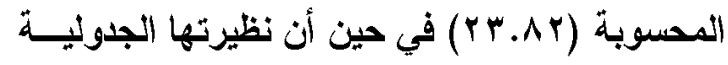

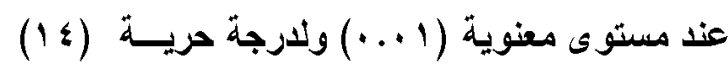

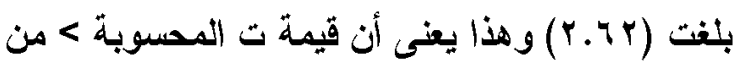

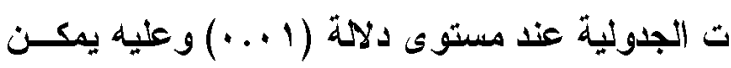

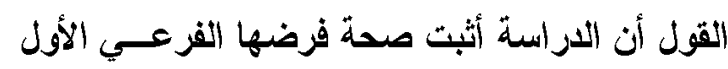
بحود ثقة (9 ه . .) وجود فزوق ذات دلاية إحصـائية

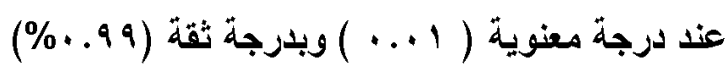

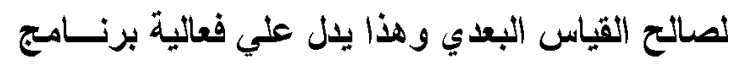
التدخل المهني من منظور الممارسة العامة لتحقيـق

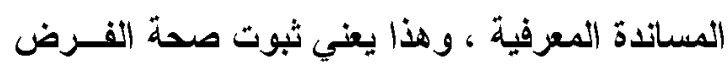
الفرعي الاول : " انه توجد فروق ذات دلالمة احصائية 
المسباندة الاجتماعية لاسـر اطفال متلازمة داون

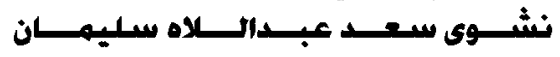

من خلال نتائج الاراسة الحالية تم التوصل لمجموعه من المستخلصات التي يمكن عزضها في الاتي : 1- توصلت الاراسة بوجه عام الي اثبات صحه

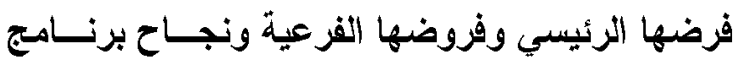

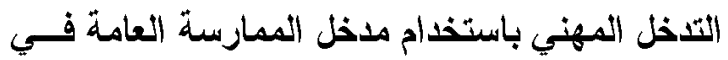
الخدمة الاجتماعية لتحقيق المساندة الاجتماعية لاسر

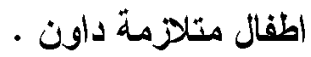

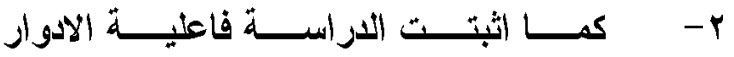

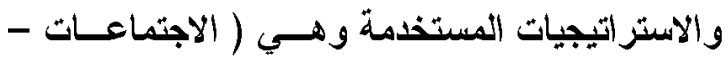

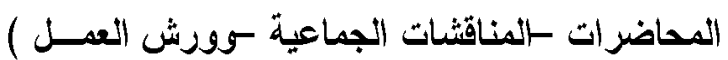
ونجاحها في تحقيق المساندة الاجتماعية لاسر اطفــال متلازمة داون

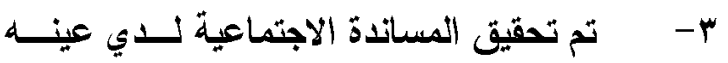
الار اسة وتزويدهم بقدر من المعارف التي تفيدهم في نهي

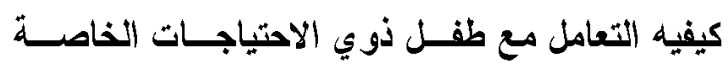
وكيفية تقبل هذا الطفل . ثالثا :مقترحات الدراسة:

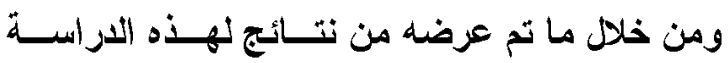

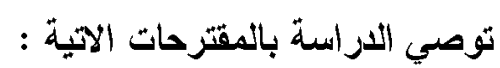

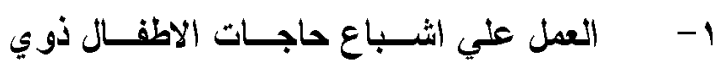
الاحتياجات الخاصة في المؤسسة من خلا الثل الثـر اكهم

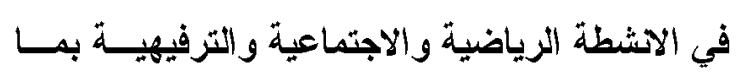
يتتاسب ميع امكانيتهم ومييولهم واتجاهاتهم .

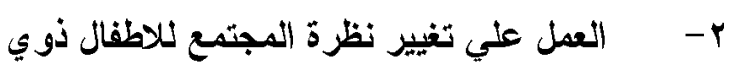

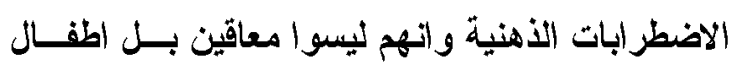

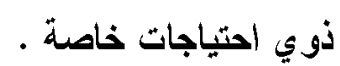

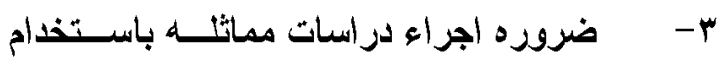

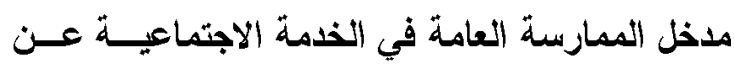

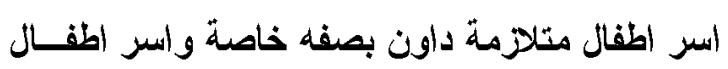
ذوي الاحتياجات الخاصة بصفه عامه

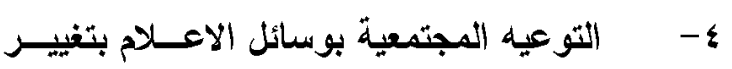

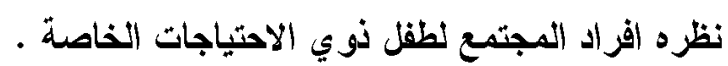

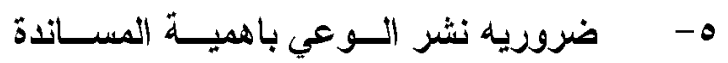

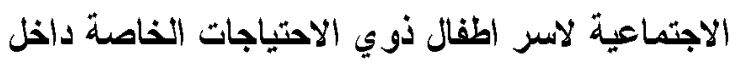

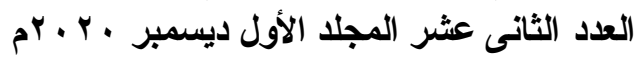

يمكن القول أن الدزاسة أثبت صحة فرضها الفرعـي

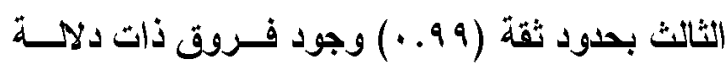

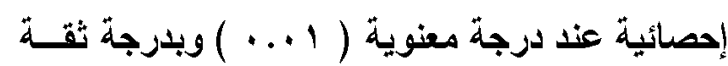

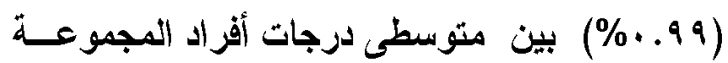
التجريبية فى تحقيق المساندة الوجدانية لاسر متلازمة دونة

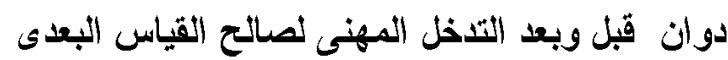
ومن خلال ثبوت صحة الفروض الفرعيـة للادرســة والمتمثلة في : ونلان فئ

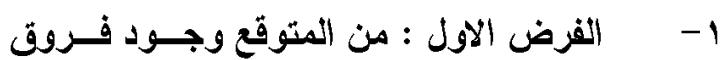

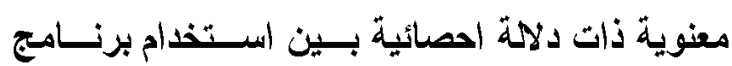

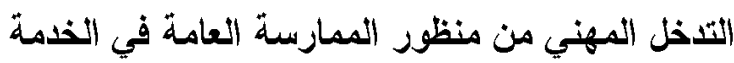
الاجتماعية وتحقيق المساندة المعرفية لاســر اطفــــال

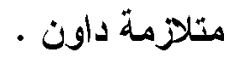

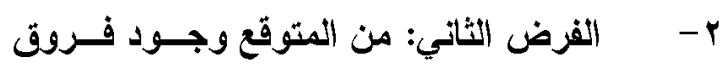

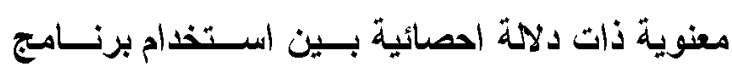

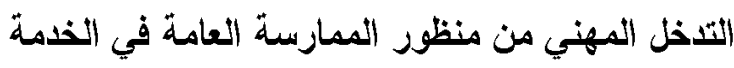
الاجتماعية وتحقيق المساندة السلوكية لاســر اطفــال

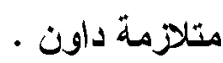

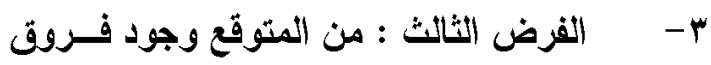

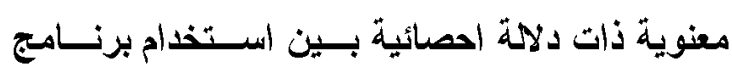

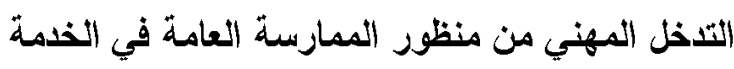
الاجتماعية وتحقيق المساندة الوجدانية لاسر اطفــال

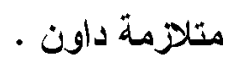

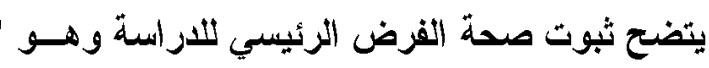
من المتوقع وجود فروق معنوية ذات دلالة احصــائية

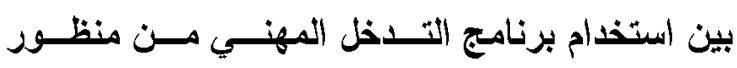

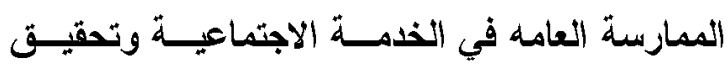

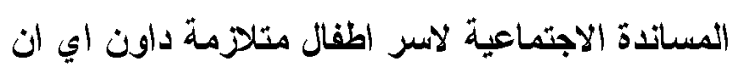

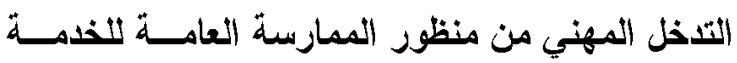

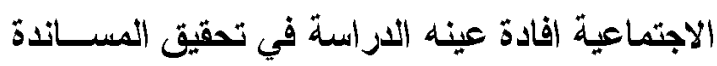

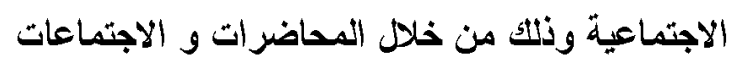
والمناقشات وورش العمل التي قامت بتنفيذها الباحثة اثناء تطبيق برنامج التدخل المهني . ثانيا : المستخلصات العامة للار اسة : 
المسـاندة الاجتماعية لاسـر اطفال متلازمة داون

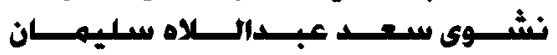

المجلة العلمية للخدمة الاجتماعية

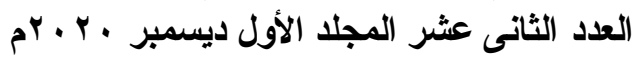

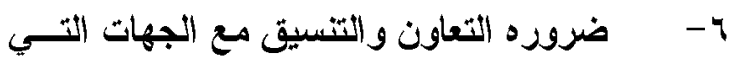

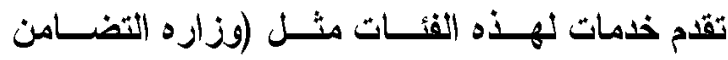

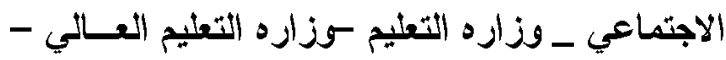

والجامعه- و المؤسسات المجتمعية) 
المسـاندة الاجتماعية لاسر اطفال متلازمة داون

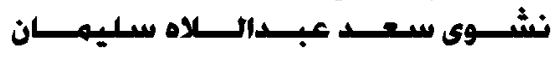

with a child diagnosed with an autism spectrum disorder, doctor of social work, university of Pennsylvania ,p.44.

Bruce Jenny and Others(2007); Blind and partially sighted people is perceptions of

Their inclusion family and friends, Journal British of visual .impairment,vol,25, p.p. 68- 85
المجلة العلمية للخدمة الاجتماعية

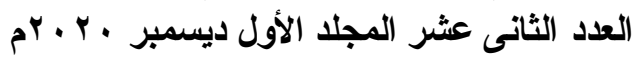

\section{المراجع - - الم}

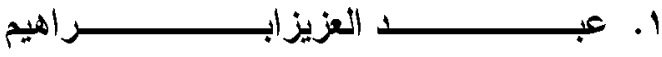

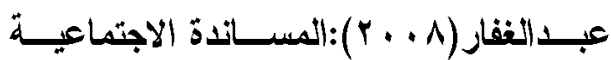

وتأهيل المعاقين بدنيا اوحركيا, بحث منشور

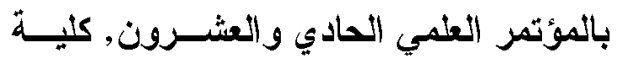

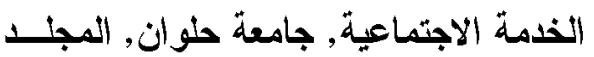

$$
\text { الثانى عثر. }
$$

r. عبد المنصف حسن على(1 +. ب): ممارسة

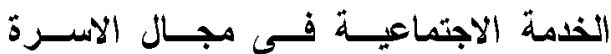

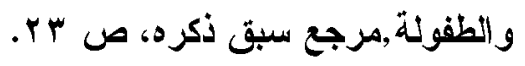

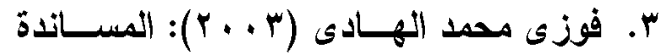

الإجتماعية في حالة أزمة الإصابة بـالمرض المرف

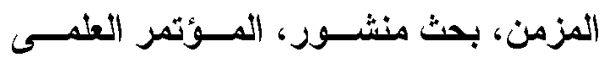

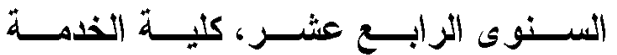

الإجتماعية ، جامعة القاهرة، فرع الفيوم.

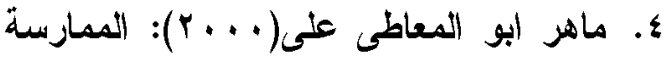

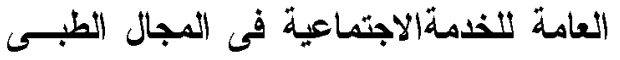

ورعاية المعاثين, مركز نشر وتوزيع الكتاب,

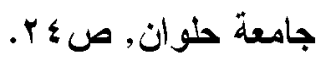

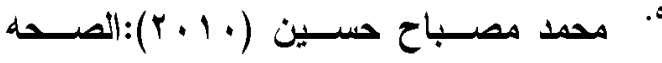

النفسية لاي امهات متلامة داون في قطاع

غزة وعلاقتها ببعض المتغيـرات ، رسبـــاله

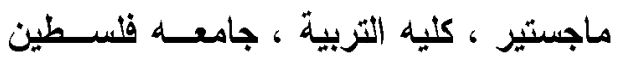

?

צ. يوسف محمد عبد الحميد(ه + . r):المســاندة

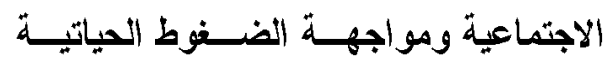

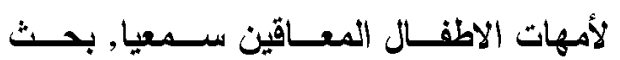

منشور , بمجلــة العـددالثامن و العثــرون

الجزء الاول, كليــة الخدمــة الاجتماعيــة,

جامعة حلو ان.

1- Jennifer c. plumb(2011); the impact

of social work support and family resilience on parental stress in families 